\title{
Concordance Modeling With a Gold Standard for Variables From the Three-Parameter Gamma Distribution
}

Márcio Paulo de Oliveira (Corresponding Author)

Federal University of Technology - Paraná (UTFPR)

Rua Cristo Rei, 19, Toledo, Paraná, 85902-490, Brazil

Tel: +55 (45) 3379-6800Ｅ-mail: marciooliveira@utfpr.edu.br

\author{
Miguel Angel Uribe-Opazo \\ Western Paraná State University - (UNIOESTE) \\ Rua Universitária, 1619, Cascavel, Paraná, 85819-170, Brazil \\ Tel: +55 (45) 3220-3000Ｅ-mail: miguel.opazo@unioeste.br \\ Manuel Galea \\ Pontificia Universidad Católica de Chile \\ Avda. Libertador Bernardo O'Higgins, 340, Santiago, Chile \\ Tel: (562) 23544000 E-mail:mgalea@mat.uc.cl \\ Jerry Adriani Johann \\ Western Paraná State University - (UNIOESTE) \\ Rua Universitária, 1619, Cascavel, Paraná, 85819-170, Brazil \\ Tel: +55 (45) 3220-3000Ｅ-mail: jerry.johann@hotmail.com
}

Received: Nov. 6, 2019

doi:10.5296/jas.v8i2.15761
Accepted: Dec. 24, 2019 Published: Jan. 3, 2020

URL: https://doi.org/10.5296/jas.v8i2.15761 


\section{Abstract}

A way to compare two or more measurements for the same random variable can be achieved by using a negligible error reference measurement, which is called the gold standard, obtained by consolidated measurement methods. This paper presents a new methodology for comparing measurements in the presence of a gold standard with random variables from the multivariate three-parameter (shape, scale, and location) gamma distribution. The errors between gold standard measures and approximate measures have a gamma difference distribution with the same three parameters of the gamma distribution. The concordance measurements were obtained by mean of a coefficient, which measures the degree of agreement as a ratio between the variances of the gold standard and the errors. The developed methodology is illustrated with climatic data which is divided into four ranges. The measurements analyzed are rainfall forecasts of the following four national centers: Canadian Meteorological Center (CMC), European Center for Medium-Range Weather Forecasts (ECMWF), National Centers for Environmental Prediction (NCEP), and Center for Weather Forecasting and Climate Studies (CPTEC). The forecast range was 240 hours for the West mesoregion of Paraná - Brazil, and in the October 1-March 31 period of the 2010/2011 $-2015 / 2016$ harvest years. The period was selected because it is related to soybean crop development in the region and because several crop estimation models use rainfall forecast data in this period. The methodology applied spatially indicated the center to be selected in each geographical location according to each rainfall range interval. The gamma model fit well with the data and is an alternative to the normal one for modelling rainfall, in particular to estimate concordances between rainfall forecasts and the gold standard, which are used to improve the selection of rainfall forecast centers.

Keywords: coefficient of agreement, spatial data, parameter estimates, rainfall forecast, multivariate gamma distribution

\section{Introduction}

The three-parameter (shape, scale, and location) gamma probability distribution according to Johnson et al. (1994) has several applications in stochastic modeling and hydrology. The three-parameter $\alpha$ (shape), $\beta$ (scale), and $\gamma$ (location) gamma probability density function is defined by Mathal and Moschopoulos (1992) as:

$$
f(x ; \alpha, \beta, \gamma)=\frac{1}{\beta^{\alpha} \Gamma(\alpha)}(x-\gamma)^{\alpha-1} \exp -\left\{\left(\frac{x-\gamma}{\beta}\right)\right\},
$$

in which $x>0, \alpha>0, \beta>0, \gamma \in \mathbb{R}$ and $\Gamma(\alpha)$ is the gamma function. The function (1) is central in defining the various forms to the multivariate gamma distribution whose marginal are gamma distributions. The literature presents several particular application cases for the multivariate gamma distribution that include bivariate cases whose discussion can be found in McKay (1934), Cherian (1941), Jensen (1970), Royen (1991), Mathal and 
Moschopoulos (1992), and references cited therein.

For evaluation of the degree of agreement (concordance) for measurements of a random variable with gamma distribution which were obtained by $p$ approximation methods, one can use the standard model (Lord \& Novick, 1968; Donner, 1986; Fleiss, 1999; Galea, 2013) of the reproducibility for measures (agreement) with respect to a reference measure, called gold standard,

$$
y_{i j}=x_{i}+\varepsilon_{i j}
$$

in which, $\varepsilon_{i j}$ is the random observation measurement error for the unity $i=1, \ldots, n$ of the method $\mathrm{j}=1, \ldots, \mathrm{p}, y_{i j}$ is the measurement performed via the $\mathrm{j}$-th method on the $\mathrm{i}$-th unity, $x_{i}$ is the gold-standard-based measurement on the i-th unity, with a mean of $E\left[x_{i}\right]=\mu$ and variance of $\operatorname{Var}\left[x_{i}\right]=\phi$; considering $\varepsilon_{i j}$ independent of $x_{i}$, with a mean of $E\left[\varepsilon_{i j}\right]=0$ and variance of $\operatorname{Var}\left[\varepsilon_{i j}\right]=\sigma_{j}^{2}$.

The model (2) can be written in matrix notation (Laurent, 1998) as

$$
\boldsymbol{Y}_{i}=x_{i} \mathbf{1}_{p}+\boldsymbol{\epsilon}_{i},
$$

in which $\boldsymbol{Y}_{i}=\left(y_{i 1}, y_{i 2}, \ldots, y_{i p}\right)^{T}, \mathbf{1}_{p}$ is a vector of ones and $\boldsymbol{\epsilon}_{i}=\left(\varepsilon_{i 1}, \varepsilon_{i 2}, \ldots, \varepsilon_{i p}\right)^{T}$. Let $Z_{i}=\left(x_{i}, \mathbf{Y}_{i}^{T}\right)^{T}$, a vector $q \times 1$, with $q=p+1$, of the measurements performed via gold standard and the approximation methods on the i-th unity.

\section{Gamma Model Specification}

Suppose that the random variables in the vector $\boldsymbol{Z}_{i}$ are independent and identically distributed (iid) with gamma distribution, i.e., $x \sim \operatorname{Gama}\left(\alpha_{1}, \beta, \gamma_{1}\right)$ and $y_{j} \approx \operatorname{Gama}\left(\alpha_{j}, \beta, \gamma_{j}\right), j=2, \ldots, q$. Let $R_{1}=x, R_{2}=x+y_{1}, \ldots, R_{q}=x+y_{1}+\cdots+y_{p}$, with $q=p+1$. The joint distribution of $\boldsymbol{R}=\left(R_{1}, R_{2}, \ldots, R_{q}\right)$ is a $q$-variate gamma 


\section{Macrothink}

distribution Mathal and Moschopoulos (1992) defined by the density function given by

$$
\begin{aligned}
f_{R}\left(r_{1}, r_{2}, \ldots, r_{q}\right)= & \frac{\left(r_{1}-\gamma_{1}\right)^{\alpha_{1}-1}\left(r_{2}-r_{1}-\gamma_{2}\right)^{\alpha_{2}-1} \ldots\left(r_{q}-r_{q-1}-\gamma_{q}\right)^{\alpha_{q}-1}}{\beta^{\alpha_{q}^{*}} \prod_{l=1}^{q} \Gamma\left(\alpha_{l}\right)} \\
& \times \exp -\left\{\left(\frac{r_{q}-\sum_{l=1}^{q} \gamma_{l}}{\beta}\right)\right\},
\end{aligned}
$$

in which $r_{i}>0, \alpha_{l}>0, \beta>0, \gamma_{l} \in \mathbb{R}, r_{l-1}+\gamma_{l}<r_{l}, \gamma_{l}<r_{l}, \alpha_{q}^{*}=\alpha_{1}+\alpha_{2}+\cdots+\alpha_{q}$, $r_{0}=0$, for $l=1, \ldots, q$ and zero elsewhere.

The multivariate gamma distribution given in (4) has several important properties (Mathal \& Moschopoulos, 1992) some of them are:

i) The marginal distribution of $R_{l}$ are three-parameter gamma with density function given in

(1), i.e., $\quad R_{l} \approx \operatorname{Gama}\left(\alpha_{l}^{*}, \beta, \gamma_{l}^{*}\right), \quad$ which $\quad \alpha_{l}^{*}=\alpha_{1}+\cdots+\alpha_{l} \quad$ and $\gamma_{l}^{*}=\gamma_{1}+\cdots+\gamma_{l}$ for $l=1, \ldots, q$.

ii) The mean and variance of $R_{l}$ are, respectively, given by

$$
\begin{aligned}
& E\left(R_{l}\right)=\beta \alpha_{l}^{*}+\gamma_{l,}^{*} \\
& \operatorname{Var}\left(R_{l}\right)=\beta^{2} \alpha_{l}^{*} .
\end{aligned}
$$

iii) The correlation matrix $\boldsymbol{P}_{R}$ of $\mathrm{R}$ has a positive correlation between $R_{l}$ and $R_{m}$ and is given by

$$
\operatorname{Corr}\left(R_{l}, R_{m}\right)=\sqrt{\frac{\alpha_{l}^{*}}{\alpha_{m}^{*}}}
$$

in which $l, m=1, \ldots, q$.

iv) The covariance of $R_{l}$ and $R_{m}$, for $l<m$ is 


$$
\operatorname{Cov}\left(R_{l}, R_{m}\right)=\operatorname{Cov}\left(R_{l}, R_{l}+V_{l+1}+\cdots+V_{m}\right)=\operatorname{Var}\left(R_{l}\right)=\beta^{2} \alpha_{l}^{*},
$$

v) The covariance matrix of the vector $\boldsymbol{R}$ denoted by $\boldsymbol{\Sigma}_{\boldsymbol{R}}$, is given by

$$
\mathbf{\Sigma}_{R}=\left(\begin{array}{cccc}
\sigma_{1}^{2} & \sigma_{1}^{2} & \cdots & \sigma_{1}^{2} \\
\sigma_{1}^{2} & \sigma_{1}^{2}+\sigma_{2}^{2} & \cdots & \sigma_{1}^{2}+\sigma_{2}^{2} \\
\vdots & \vdots & & \vdots \\
\sigma_{1}^{2} & \sigma_{1}^{2}+\sigma_{2}^{2} & \cdots & \sigma_{1}^{2}+\cdots+\sigma_{q}^{2}
\end{array}\right)
$$

in which $\sigma_{l}^{2}=\alpha_{l} \beta^{2}$ and $\left|\mathbf{\Sigma}_{R}\right|=\prod_{l=1}^{q} \alpha_{l}^{2}, l=1, \ldots, q$.

Suppose $r_{1}=x, r_{2}=x+y_{1}, \quad r_{q}=x+y_{1}+\cdots+y_{p}$, then

$$
f_{z}\left(x, y_{1}, \ldots, y_{p}\right)=f_{R}\left(r_{1}, r_{2}, \ldots, r_{q}\right)|\mathrm{J}|
$$

in which $\mathbf{J}$ is the Jacobean of the transformation of order $q \times q$ given by

$$
\mathbf{J}=\frac{\partial\left(r_{1}, r_{2}, \ldots, r_{q}\right)}{\partial\left(x, y_{1}, \ldots, y_{p}\right)}=\left(\begin{array}{cccc}
\frac{\partial r_{1}}{\partial x} & \frac{\partial r_{2}}{\partial x} & \cdots & \frac{\partial r_{q}}{\partial x} \\
\frac{\partial r_{1}}{\partial y_{1}} & \frac{\partial r_{2}}{\partial y_{1}} & \cdots & \frac{\partial y_{p}}{\partial y_{1}} \\
\vdots & \vdots & & \vdots \\
\frac{\partial r_{1}}{\partial y_{p}} & \frac{\partial y_{1}}{\partial y_{p}} & \cdots & \frac{\partial y_{p}}{\partial y_{p}}
\end{array}\right)
$$

then,

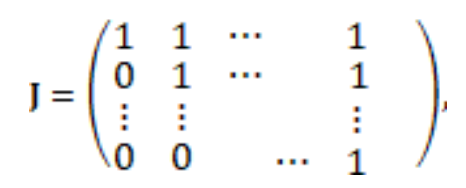

note that the $|\mathbf{J}|=1$, thus one has 


$$
f_{z}\left(x, y_{1}, \ldots, y_{p}\right)=f_{R}\left(x, x+y_{1}, \ldots, x+y_{1} \ldots+y_{p}\right) .
$$

\subsection{Parameter Estimation}

Let $f_{z}$ be the probability density function of $\boldsymbol{Z}$, which is given from (11) as

$$
\begin{aligned}
f_{z}\left(x, y_{1}, \ldots, y_{p}\right)=\frac{\left(x-\gamma_{1}\right)^{\alpha_{1}-1} \exp -\left\{\left(\frac{x-\gamma_{1}}{\beta}\right)\right\}}{\beta^{\alpha_{1}} \Gamma\left(\alpha_{1}\right)} \cdots \\
. \frac{\left(y_{p}-\gamma_{q}\right)^{\alpha_{q}-1} \exp -\left\{\left(\frac{y_{p}-\gamma_{q}}{\beta}\right)\right\}}{\beta^{\alpha_{q}} \Gamma\left(\alpha_{q}\right)} .
\end{aligned}
$$

Thus, the estimation of $(2 q+1)$ parameters of the $q$-varied gamma distribution given in (12) can be performed by maximum product spacings method (Cheng \& Amin, 1983). Considering the ordered observations of the components of the vector $Z_{i}=\left(x_{i}, \mathbf{Y}_{i}^{T}\right)^{T}$, i.e., $Z_{i-1}<Z_{i}, \quad$ for $i=1, \ldots, n+1$, in which $Z_{0}=0, \quad Z_{n+1}=\infty$. Let $D_{l i}\left(\theta_{l}\right)=F\left(z_{l i} ; \theta_{l}\right)-F\left(z_{l i-1} ; \theta_{l}\right), \theta_{l}=\left(\alpha_{l}, \beta, \gamma_{l}\right) \quad l=1, \ldots, q$, where $z_{1 i}=x_{i}, \ldots$ $z_{\text {qi }}=y_{i p}$, then

$$
D_{l i}\left(\theta_{l}\right)=\int_{z_{l i-1}}^{z_{l i}} \frac{\left(z_{l}-\gamma_{l}\right)^{\alpha_{l}-1} \exp -\left\{\left(\frac{z_{l}-\gamma_{l}}{\beta}\right)\right\}}{\beta^{\alpha_{l}} \Gamma\left(\alpha_{l}\right)}
$$

in which $D_{l 1}\left(\theta_{l}\right)=F\left(z_{l 1} ; \theta_{l}\right)$ and $D_{l n+1}\left(\theta_{l}\right)=1-F\left(z_{l n} ; \theta_{l}\right)$, with $\sum_{i=1}^{n+1} D_{l i}=1$.

The maximum space product method requires maximization of the geometric mean of the spaces given by

$$
G_{l}=\left(\prod_{i=1}^{n+1} D_{l i}\right)^{1 /(n+1)}
$$

or, equivalently, its $\operatorname{logarithm} H_{l}=\log G_{l}$, in which 


$$
H_{l}=\log G_{l}=\frac{1}{n+1}\left(\sum_{i=1}^{n+1} \log D_{l i}\right)
$$

for $l=1, \ldots, q$. The maximum product of spacings estimator for $\theta_{l}$ is the one which maximizes the logarithm of the geometric mean of sample spacings, i.e., $\hat{\theta}_{l}=\arg \max _{\theta_{l} \in \Theta} S_{n}\left(\theta_{l}\right)$ in which

$$
S_{l n}\left(\theta_{i}\right)=\log \sqrt[n+1]{\prod_{i=1}^{n+1} D_{l i}}=\log \left(F\left(z_{l i} ; \theta_{l}\right)\right)+\sum_{i=2}^{n} \log \left(D_{l i}\left(\theta_{l}\right)\right)+\log \left(1-F\left(z_{l n} ; \theta_{l}\right)\right)
$$

The estimates of $(2 q+1)$ parameters were obtained by maximizing the function given in (16), which is performed using the software $\mathrm{R}$ ( $\mathrm{R}$ Core Team, 2019) via function optim from package stats, and with the method BFGS (Broyden, 1970; Fletcher, 1970; Goldfarb, 1970; Shanno, 1970).

\subsection{Gamma Difference Model}

Suppose that reference measurement $x_{i}$ and approximate measurements $\mathbf{Y}_{i}^{T}$ are independent, with gamma distributions, i.e., $x \sim \operatorname{Gama}\left(\alpha_{1}, \beta, \gamma_{1}\right) \quad$ and $y_{j} \sim \operatorname{Gama}\left(\alpha_{j}, \beta, \gamma_{j}\right)$, in which $j=2, \ldots, q$. The errors $\varepsilon_{j}$ are obtained via model (2)

and given by $\varepsilon_{j}=y_{j}-x$. The density function of $\varepsilon_{j}$ (Mathal, 1993) $g\left(\varepsilon_{j}\right)$ is given by

$$
g\left(\varepsilon_{i j}\right)=\left\{\begin{array}{c}
c_{1}\left(\varepsilon_{i j}-\left(\gamma_{1}+\gamma_{j}\right)\right)^{\left(\alpha_{1}+\alpha_{j}\right) / 2-1} e^{-\left(\left(s_{i j}-\left(\gamma_{1}+\gamma_{j}\right)\right) / 2\right)(1 / \beta-1 / \beta)} \\
-W_{\left(\alpha_{1}-\alpha_{j}\right) / 2,\left(1-\alpha_{1}-\alpha_{j}\right) / 2}\left(\beta_{0}\left(\varepsilon_{i j}-\left(\gamma_{1}+\gamma_{j}\right)\right)\right) \\
\text { for }\left(\varepsilon_{i j}-\left(\gamma_{1}+\gamma_{j}\right)\right)>0 \\
c_{2}\left(-\left(\varepsilon_{i j}-\left(\gamma_{1}+\gamma_{j}\right)\right)\right)^{\left(\alpha_{1}+\alpha_{j}\right) / 2-1} e^{\left(\left(\varepsilon_{i j}-\left(\gamma_{1}+\gamma_{j}\right)\right) / 2\right)(1 / \beta-1 / \beta)} \\
-W_{\left(\alpha_{j}-\alpha_{1}\right) / 2,\left(1-\alpha_{1}-\alpha_{j}\right) / 2}\left(-\beta_{0}\left(\varepsilon_{i j}-\left(\gamma_{1}+\gamma_{j}\right)\right)\right) \\
\text { for }\left(\varepsilon_{i j}-\left(\gamma_{1}+\gamma_{j}\right)\right) \leq 0,
\end{array}\right.
$$


in which $\beta_{0}=2 / \beta \quad, \quad c_{1}$ and $c_{2}$ are defined by

$c_{1}^{-1}=\Gamma\left(\alpha_{1}\right) \beta^{\left(\alpha_{1}-\alpha_{j}\right) / 2} \beta^{\left(\alpha_{j}-\alpha_{1}\right) / 2}(\beta+\beta)^{\left(\alpha_{1}+\alpha_{j}\right) / 2}$

and

$c_{2}^{-1}=\Gamma\left(\alpha_{2}\right) \beta^{\left(\alpha_{1}-\alpha_{j}\right) / 2} \beta^{\left(\alpha_{j}-\alpha_{1}\right) / 2}(\beta+\beta)^{\left(\alpha_{1}+\alpha_{j}\right) / 2}$. The mean and variance of $\varepsilon_{j}$ are,

respectively, given by

$$
\begin{gathered}
E\left(\varepsilon_{j}\right)=\gamma_{1}-\gamma_{j}+\left(\alpha_{1}-\alpha_{j}\right) \beta_{x} \\
\operatorname{Var}\left(\varepsilon_{j}\right)=\left(\gamma_{1}-\gamma_{j}\right)^{2}+\left(1+\alpha_{1}\right) \alpha_{1} \beta^{2}+\left(1+\alpha_{j}\right) \alpha_{j} \beta^{2} \\
+2 \alpha_{1} \beta\left(\gamma_{1}-\gamma_{j}\right)-2 \alpha_{j} \beta\left(\gamma_{1}-\gamma_{j}\right)-2 \alpha_{1} \alpha_{j} \beta^{2} \\
-\gamma_{1}{ }^{2}-\gamma_{j}{ }^{2}+2 \gamma_{1} \gamma_{j}-2 \gamma_{1}\left(\alpha_{1}-\alpha_{j}\right) \beta \\
+2 \gamma_{j}\left(\alpha_{1}-\alpha_{j}\right) \beta-\left(\alpha_{1}-\alpha_{j}\right)^{2} \beta^{2} .
\end{gathered}
$$

\section{Coefficient of Agreement}

The ad hoc coefficient (Lin, 1989; Laurent, 1998) used to evaluate the measure of agreement (concordance) between $\mathrm{p}$ approximate methods and the gold standard, which is widely used in the sciences (Galea, 2013) for evaluating the reproducibility of the measurements is given by

$$
\rho_{j}=\phi /\left(\phi+\sigma_{j j}\right)
$$

The estimator of (20) is

$$
\hat{\rho}_{j}=\hat{\phi} /\left(\widehat{\phi}+\hat{\sigma}_{j j}\right)
$$

in which $\hat{\phi}=\widehat{\operatorname{Var}}\left(R_{1}\right)$ and $\widehat{\sigma}_{j j}=\widehat{\operatorname{Var}}\left(\varepsilon_{j}\right)$, for $j=1, \ldots, p$, according to the equations (6) and (18), respectively. 


\subsection{Confidence Interval}

The confidence interval for $\rho_{j}$ can be obtained via the bootstrapping pairs method according to Chernick and LaBudde (2011), using the following steps:

1. Resample with the replacement pairs of observations, $b$ times, yielding vector $\boldsymbol{Z}_{b i}=\left(x_{b i}, \mathbf{Y}_{b i}^{T}\right)^{T}, \quad$ in which $\boldsymbol{Y}_{b i}=\left(y_{b i 1}, y_{b i 2}, \ldots, y_{b i p}\right)^{T}$

2. Generate the variables $R_{b 1}, R_{b 2}, \quad R_{b q}$ using convolutions;

3. Estimate the $(2 \mathrm{q}+1)_{b}$ parameters of the $q$-varied gamma distribution for $\boldsymbol{Z}_{b i}$;

4. Compute estimates for the concordances $\hat{\rho}_{b j}$;

5. Build up the vector $\hat{\boldsymbol{\rho}}_{b j}=\left(\hat{\rho}_{b 1}, \hat{\rho}_{b 2}, \ldots, \hat{\rho}_{b p}\right)^{T}$;

6. Estimate the confidence intervals with $\alpha_{\text {sig }} \%$ for $\rho_{j}$, i.e., $\operatorname{IC}\left[\hat{\rho}_{j\left(\alpha_{s i g} / 2\right)}, \hat{\rho}_{j\left(1-\alpha_{\text {sig }} / 2\right)}\right]$, in which $b=1, \ldots, 1000, i=1, \ldots, n, j=1, \ldots, p$ and $\hat{\rho}_{j\left(\kappa_{\text {sig }} / 2\right)}$ is the empirical percentile calculated with the bootstrap replicates from step (6).

\section{Climate Data Application}

For the agreement analysis with the multivariate gamma model, the dataset from TIGGE base, which is used in several studies (Aminyavari et al., 2018; Jha et al., 2018), were spatially stratified by selection of geographic coordinates $\left(55^{\circ} \mathrm{W}, 53^{\circ} \mathrm{W}, 27^{\circ} \mathrm{S}, 23^{\circ} \mathrm{S}\right)$, corresponding to the rectangle containing the state of Paraná - Brazil (Figure 1). The pixels (P) have a dimension of $0.5^{\circ} \times 0.5^{\circ}$, with 84 pixels in total. Values from each pixel were obtained by database interpolation.

This study considered 75 meteorological stations from National Water Agency - Brazil (ANA) and 13 virtual stations indicated by the centroids of pixels in the mesoregion West of Paraná Brazil (Figure 1). The correspondence between pixels (virtual stations) and ANA stations were obtained considering to each pixel a group of ANA stations with distance less than or equal to $0.36^{\circ}$ (about $40 \mathrm{~km}$ ) from the centroid of pixels. 


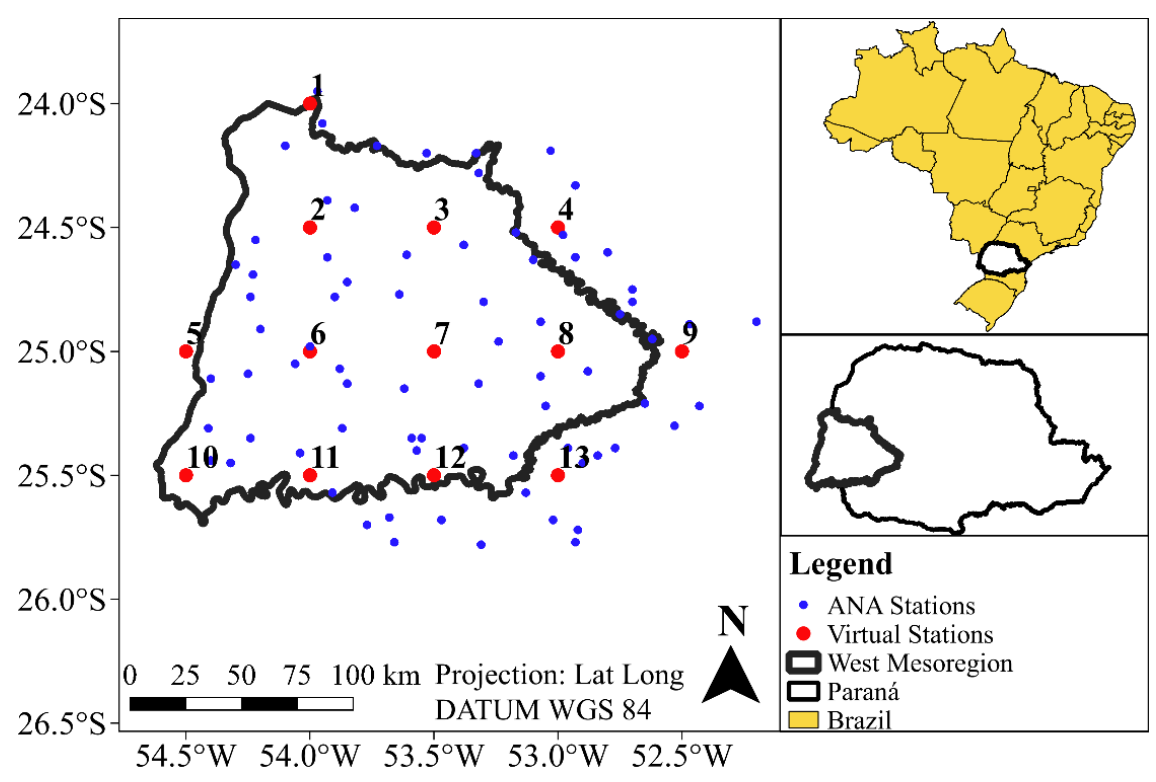

Figure 1. Location map of the West mesoregion of Paraná, containing the ANA physical meteorological stations, virtual stations corresponding to CMC, ECMWF, NCEP and CPTEC

A temporal stratification was performed, selecting October 1-March 31 of the 2010/2011 $-2015 / 2016$ harvest years as the temporal range. The range was selected because the state of Paraná is one of the largest soybean producers in Brazil, and the Agricultural Defense Agency of Paraná - Brazil (ADAPAR, 2018) establishes the proper period for sowing soybean crops of each agricultural year. Thus, the period was selected because it is related to soybean crop development in the region and because several crop estimation models use rainfall forecast data in this period. Agrometeorological variables directly influence crop yield estimation models (Battisti et al., 2018). In soybean culture, water availability is important, especially, during two development stages: germination-emergence and flowering-grain filling. (Rodrigues et al., 2017).

The rainfall forecast models of the TIGGE base used in this research were Canadian CMC, European ECMWF, North American NCEP and Brazilian CPTEC. The reference datasets, gold standard, were obtained of daily precipitation from ANA meteorological stations. Missing data were disregarded in the correspondences.

Descriptive statistics are presented in Table 1, for the data grouped in ten-day periods, corresponding to the 13 pixels in West mesoregion of Paraná - Brazil, and in the October 1-March 31 period of the 2010/201 -2015/2016 harvest years. The period includes soybean sowing in Paraná (Meotti et al., 2012; Bornhofen et al., 2015).

Several studies reveal the relation between spatial variability of the rainfall and the crop yield (Bezabih \& Di Falco, 2012; Moraes et al., 2014; Jajoria et al., 2015). The crop yield estimation models are sensitive to variable precipitation (Cera et al., 2017). Missing ten-day periods were not found in ANA stations. The number of missing ten-day periods of centers are: 2 in CMC, 1 in ECMWF, 10 in NCEP, and 79 in CPTEC. 
Table 1. Descriptive statistics of the 977 ten-day periods in the 13 pixels in West mesoregion of Paraná - Brazil, for the measurements of ANA stations (A), ten-day rainfall forecasts of centers CMC (B), ECMWF (C), NCEP (D) and CPTEC (E)

\begin{tabular}{|c|c|c|c|c|c|c|c|c|c|c|c|c|c|c|c|c|c|}
\hline$P$ & $\mathrm{~N}$ & $\mathrm{O}$ & Min & Q1 & Q2 & Med & Q3 & Max & $\mathrm{P}$ & $\mathrm{N}$ & $\mathrm{O}$ & $\operatorname{Min}$ & Q1 & Q2 & Med & Q3 & Max \\
\hline \multirow{5}{*}{1} & \multirow{5}{*}{4} & $\mathrm{~A}$ & 0.00 & 17.62 & 44.43 & 49.84 & 71.62 & 170.65 & \multirow{5}{*}{8} & \multirow{5}{*}{9} & A & 0.00 & 17.10 & 40.67 & 52.39 & 75.37 & 210.44 \\
\hline & & B & 0.00 & 28.59 & 52.75 & 58.59 & 80.89 & 213.31 & & & B & 0.00 & 29.28 & 53.78 & 61.32 & 84.38 & 261.62 \\
\hline & & $\mathrm{C}$ & 0.00 & 34.92 & 62.27 & 67.30 & 93.00 & 266.00 & & & $\mathrm{C}$ & 0.29 & 36.24 & 62.89 & 69.49 & 97.04 & 251.93 \\
\hline & & $\mathrm{D}$ & 0.00 & 34.67 & 59.96 & 67.12 & 91.86 & 240.50 & & & D & 0.00 & 29.21 & 55.94 & 62.86 & 89.04 & 257.42 \\
\hline & & $\mathrm{E}$ & 0.00 & 20.03 & 35.68 & 39.18 & 52.17 & 187.56 & & & E & 0.37 & 23.03 & 38.60 & 44.00 & 58.04 & 169.63 \\
\hline \multirow{5}{*}{2} & \multirow{5}{*}{9} & $\mathrm{~A}$ & 0.74 & 23.51 & 50.02 & 56.91 & 79.86 & 189.48 & \multirow{5}{*}{9} & \multirow{5}{*}{11} & A & 0.00 & 20.46 & 43.23 & 51.18 & 73.14 & 208.91 \\
\hline & & B & 0.00 & 28.56 & 57.12 & 63.25 & 88.00 & 229.75 & & & B & 0.00 & 28.50 & 51.75 & 60.03 & 83.44 & 229.62 \\
\hline & & $\mathrm{C}$ & 0.01 & 37.38 & 62.38 & 66.57 & 91.50 & 256.41 & & & $\mathrm{C}$ & 0.17 & 30.09 & 54.36 & 60.53 & 85.06 & 231.01 \\
\hline & & $\mathrm{D}$ & 0.00 & 31.72 & 55.68 & 64.70 & 88.64 & 291.92 & & & D & 0.00 & 29.62 & 55.02 & 64.37 & 90.66 & 270.89 \\
\hline & & $\mathrm{E}$ & 0.27 & 21.90 & 37.50 & 42.97 & 57.74 & 168.25 & & & E & 0.26 & 20.84 & 36.32 & 41.37 & 55.63 & 179.49 \\
\hline \multirow{5}{*}{3} & \multirow{5}{*}{8} & $\mathrm{~A}$ & 0.00 & 16.05 & 42.34 & 50.90 & 75.09 & 235.72 & \multirow{5}{*}{10} & \multirow{5}{*}{4} & A & 0.00 & 16.55 & 38.48 & 50.63 & 72.05 & 212.15 \\
\hline & & B & 0.00 & 29.26 & 57.00 & 62.00 & 83.88 & 252.88 & & & B & 0.12 & 3100 & 56.03 & 59.50 & 82.09 & 241.50 \\
\hline & & $\mathrm{C}$ & 0.00 & 34.47 & 58.35 & 64.14 & 88.27 & 247.09 & & & $\mathrm{C}$ & 0.02 & 32.38 & 56.62 & 63.04 & 86.72 & 232.10 \\
\hline & & $\mathrm{D}$ & 0.00 & 32.45 & 56.26 & 64.17 & 87.94 & 264.53 & & & D & 0.24 & 33.59 & 57.03 & 64.93 & 87.84 & 231.06 \\
\hline & & $\mathrm{E}$ & 0.11 & 19.69 & 34.29 & 39.49 & 52.93 & 178.03 & & & E & 0.32 & 31.46 & 52.57 & 57.02 & 75.84 & 236.85 \\
\hline \multirow{5}{*}{4} & \multirow{5}{*}{7} & $\mathrm{~A}$ & 0.00 & 19.04 & 41.77 & 49.54 & 74.46 & 230.11 & \multirow{5}{*}{11} & \multirow{5}{*}{6} & A & 0.00 & 13.55 & 37.50 & 52.45 & 80.43 & 237.17 \\
\hline & & $\mathrm{B}$ & 0.00 & 28.25 & 52.75 & 60.74 & 83.19 & 276.00 & & & B & 0.12 & 32.50 & 57.88 & 61.65 & 84.56 & 265.25 \\
\hline & & $\mathrm{C}$ & 0.02 & 36.51 & 62.04 & 69.37 & 95.81 & 275.99 & & & $\mathrm{C}$ & 0.07 & 30.96 & 54.22 & 61.49 & 85.47 & 217.85 \\
\hline & & $\mathrm{D}$ & 0.00 & 31.34 & 55.6 & 63.63 & 87.33 & 272.42 & & & D & 0.28 & 34.14 & 58.88 & 66.41 & 88.11 & 222.40 \\
\hline & & $\mathrm{E}$ & 0.04 & 19.24 & 33.16 & 38.47 & 52.07 & 187.50 & & & E & 0.58 & 33.07 & 53.33 & 57.90 & 76.89 & 221.84 \\
\hline \multirow{5}{*}{5} & \multirow{5}{*}{5} & $\mathrm{~A}$ & 0.00 & 19.58 & 40.38 & 46.52 & 67.18 & 181.12 & \multirow{5}{*}{12} & \multirow{5}{*}{10} & A & 0.00 & 18.32 & 43.17 & 54.22 & 80.97 & 244.36 \\
\hline & & B & 0.00 & 29.68 & 54.88 & 58.74 & 81.67 & 240.94 & & & B & 0.12 & 31.64 & 56.62 & 59.15 & 81.22 & 230.38 \\
\hline & & $\mathrm{C}$ & 0.00 & 41.01 & 66.24 & 74.73 & 104.72 & 272.02 & & & $\mathrm{C}$ & 0.14 & 30.98 & 54.17 & 61.55 & 84.78 & 251.97 \\
\hline & & $\mathrm{D}$ & 0.00 & 31.60 & 56.15 & 65.77 & 89.54 & 255.41 & & & D & 0.28 & 34.41 & 58.27 & 66.68 & 89.37 & 253.69 \\
\hline & & $\mathrm{E}$ & 0.50 & 28.75 & 47.95 & 53.13 & 70.35 & 197.00 & & & E & 0.99 & 34.26 & 55.31 & 59.88 & 79.70 & 212.90 \\
\hline \multirow{5}{*}{6} & \multirow{5}{*}{10} & $\mathrm{~A}$ & 0.00 & 16.14 & 40.24 & 49.44 & 73.26 & 203.34 & & & $\mathrm{~A}$ & 0.00 & 16.90 & 44.81 & 52.73 & 81.11 & 225.55 \\
\hline & & B & 0.00 & 28.75 & 50.75 & 56.23 & 78.75 & 206.00 & & & B & 0.12 & 32.09 & 56.38 & 59.55 & 81.09 & 223.75 \\
\hline & & $\mathrm{C}$ & 0.03 & 32.32 & 55.35 & 62.72 & 87.63 & 239.00 & 13 & 10 & $\mathrm{C}$ & 0.16 & 31.62 & 56.36 & 63.97 & 88.67 & 223.41 \\
\hline & & $\mathrm{D}$ & 0.00 & 30.68 & 55.28 & 66.04 & 92.69 & 298.62 & & & D & 0.40 & 39.93 & 65.24 & 74.81 & 98.55 & 315.34 \\
\hline & & $\mathrm{E}$ & 1.31 & 30.97 & 50.91 & 55.59 & 74.03 & 187.01 & & & E & 1.30 & 34.08 & 55.25 & 58.32 & 76.16 & 191.19 \\
\hline & & A & 0.00 & 17.03 & 43.98 & 52.75 & 79.92 & 223.98 & & & & & & & & & \\
\hline & & B & 0.00 & 30.38 & 53.44 & 59.57 & 84.66 & 277.75 & & & & & & & & & \\
\hline 7 & 6 & $\mathrm{C}$ & 0.11 & 32.38 & 52.17 & 58.67 & 79.57 & 204.00 & & & & & & & & & \\
\hline & & $\mathrm{D}$ & 0.00 & 30.26 & 58.34 & 64.99 & 90.48 & 280.92 & & & & & & & & & \\
\hline & & $\mathrm{E}$ & 0.62 & 22.83 & 38.51 & 43.72 & 58.30 & 160.17 & & & & & & & & & \\
\hline
\end{tabular}

Note: P: Pixel number, N: number of ANA stations, O: Origin center, Min: Minimum value, Q1: First quartile, Q2: Second quartile, Med: Mean, Q3: Third quartile, Max: maximum value.

The value of $100 \mathrm{~mm}$ was used as an indicator of extreme events (Zandonadi et al., 2016). The following percentages of ten-day periods above $100 \mathrm{~mm}$, according to the gold standard for each pixel, were computed (Figure 1). For pixel 1, 10,5\%; pixel 2: 16\%; pixel 3: 12,5\%; pixel 4: 11\%; pixel 5: 6,2\%; pixel 6: 12,4\%; pixel 7: 14,4\%; pixel 8: 16,3\%; pixel 9: 13,7\%; pixel 10: 14,6\%; pixel 11: 16\%; pixel 12: 17,6\%; and in pixel 13: $14,3 \%$.

The highest incidence of extreme precipitation events was identified in pixel 12, and the pixel 1 was the least affected by these events. The coefficients of variation (CV) of the gold standard with the lowest value of $36.80 \%$ were obtained in pixel 7 , and the highest value of 


\section{Macrothink

$45.90 \%$ in the pixel 4 . The CV indicated heterogeneity of values of rainfall in the stations. For the forecast centers, the CV with the lowest value of $55.60 \%$ was obtained for CPTEC in the pixel 13 and the highest value of $73.30 \%$ for NCEP in the pixel 6 . The values of the CV indicated heterogeneity of the data from the ANA stations and the TIGGE base.

The water stress is the main cause for losses in the soybean culture (Confalone et al., 2010; Nunes et al., 2016; Souza et al., 2016). For non-irrigated areas, the water deficit caused, mainly, during drought periods can increase losses in the agricultural crops (Nunes et al., 2016; Pugh et al., 2019). The spatial variability of the soybean culture and the several agricultural crops occur according to the water availability (Iglesias et al., 2012; Vivan et al., 2013; Zanon et al., 2016). Thus, crop yield estimation models to increase the reliability should consider a climatic center, which rainfall forecasts are closer to the gold standard measures in a study region. The main source of water for an agricultural system comes from rainfall, which can be modeled using a gamma distribution (Sadiq, 2014; Cristaldo, 2017; Hasan et al., 2019).

The three-parameter multivariate gamma distribution given in (4) can be used for modelling a group of variables with gamma distribution. In order to compute the degree of agreement of $\mathrm{j}$-th approximate measure with the gold standard, $\hat{\rho}_{j}$ coefficient given by equation (21), it is required to obtain the variance of the difference of random variables with gamma distribution according to the model (Mathal, 1993) given in (17).

Descriptive statistics are presented in Table 2, for the agreements $\hat{\rho}_{j}$, in which $j=1, \ldots, 4$ (centers) in the 13 pixels for each range of rainfall with data grouped in ten-day periods. The ranges were defined as follows: range $1(0,00 \mid-61,09 \mathrm{~mm})$, range $2(61,09 \mid-122,18 \mathrm{~mm})$, range $3(122,18 \mid-183,27 \mathrm{~mm})$, and range $4(183,27 \mid-244,36 \mathrm{~mm})$. 


\section{Macrothink}

Table 2. Descriptive statistics of the agreements $\hat{\rho}$ for the ranges $1-4$ in the $P=13$ pixels in each center

\begin{tabular}{|c|c|c|c|c|c|c|c|c|c|}
\hline Ranges & Center & Min & Q1 & Q2 & Med & Q3 & $\operatorname{Max}$ & SD & $\mathrm{CV}(\%)$ \\
\hline \multirow{5}{*}{$\begin{array}{l}\text { Range } 1 \\
0 \dashv 61.09 \\
\mathrm{~mm}\end{array}$} & $\begin{array}{c}\text { CMC } \\
\text { (B) }\end{array}$ & 0.233 & 0.246 & 0.250 & 0.250 & 0.256 & 0.265 & 0.009 & 3.571 \\
\hline & ECMWF & & & & & & & & \\
\hline & (C) & 0.224 & 0.244 & 0.248 & 0.247 & 0.253 & 0.264 & 0.011 & 4.294 \\
\hline & $\begin{array}{l}\text { NCEP } \\
\text { (D) }\end{array}$ & 0.225 & 0.234 & 0.239 & 0.242 & 0.252 & 0.257 & 0.011 & 4.509 \\
\hline & $\begin{array}{c}\text { CPTEC } \\
\text { (E) }\end{array}$ & 0.240 & 0.252 & 0.270 & 0.269 & 0.285 & 0.298 & 0.019 & 7.184 \\
\hline \multirow{4}{*}{$\begin{array}{c}\text { Range } 2 \\
61.09 \dashv 122.18 \\
\mathrm{~mm}\end{array}$} & $\begin{array}{c}\text { CMC } \\
\text { (B) }\end{array}$ & 0.346 & 0.354 & 0.360 & 0.361 & 0.364 & 0.377 & 0.009 & 2.484 \\
\hline & $\begin{array}{c}\text { ECMWF } \\
\text { (C) }\end{array}$ & 0.333 & 0.353 & 0.356 & 0.356 & 0.360 & 0.382 & 0.012 & 3.308 \\
\hline & $\begin{array}{c}\text { NCEP } \\
\text { (D) }\end{array}$ & 0.339 & 0.348 & 0.355 & 0.355 & 0.360 & 0.384 & 0.012 & 3.266 \\
\hline & $\begin{array}{c}\text { CPTEC } \\
\text { (E) }\end{array}$ & 0.335 & 0.359 & 0.383 & 0.372 & 0.385 & 0.398 & 0.020 & 5.354 \\
\hline \multirow{4}{*}{$\begin{array}{c}\text { Range } 3 \\
122.18 \dashv 183.27 \\
\mathrm{~mm}\end{array}$} & $\begin{array}{c}\text { CMC } \\
\text { (B) }\end{array}$ & 0.390 & 0.399 & 0.400 & 0.404 & 0.407 & 0.426 & 0.009 & 2.272 \\
\hline & $\begin{array}{c}\text { ECMWF } \\
\text { (C) }\end{array}$ & 0.378 & 0.393 & 0.403 & 0.402 & 0.412 & 0.430 & 0.015 & 3.781 \\
\hline & $\begin{array}{l}\text { NCEP } \\
\text { (D) }\end{array}$ & 0.385 & 0.389 & 0.392 & 0.395 & 0.396 & 0.422 & 0.010 & 2.438 \\
\hline & $\begin{array}{c}\text { CPTEC } \\
\text { (E) }\end{array}$ & 0.392 & 0.407 & 0.423 & 0.416 & 0.426 & 0.432 & 0.013 & 3.102 \\
\hline \multirow{4}{*}{$\begin{array}{c}\text { Range } 4 \\
183.27 \dashv 244.36 \\
\mathrm{~mm}\end{array}$} & $\begin{array}{c}\text { CMC } \\
\text { (B) }\end{array}$ & 0.410 & 0.426 & 0.430 & 0.431 & 0.432 & 0.455 & 0.011 & 2.609 \\
\hline & $\begin{array}{c}\text { ECMWF } \\
\text { (C) }\end{array}$ & 0.406 & 0.412 & 0.427 & 0.424 & 0.430 & 0.438 & 0.011 & 2.603 \\
\hline & $\begin{array}{l}\text { NCEP } \\
\text { (D) }\end{array}$ & 0.407 & 0.422 & 0.430 & 0.428 & 0.434 & 0.445 & 0.012 & 2.696 \\
\hline & $\begin{array}{c}\text { CPTEC } \\
\text { (E) }\end{array}$ & 0.417 & 0.426 & 0.437 & 0.436 & 0.444 & 0.463 & 0.013 & 2.981 \\
\hline
\end{tabular}

Note: Min: Minimum value, Q1: First quartile, Q2: Second quartile, Med: Mean, Q3: Third 
quartile, Max: maximum value, SD: standard deviation, CV: coefficient of variation.

The spatial variability of the concordances, in the study area, is indicated for the ranges 1,2 , 3, and 4 in Figure 2. The difference of concordances and the distinct spatial variation for each range in the pixels were evident.

The comparison method with a gold standard, which aims to evaluate the ratio between the variances of the gold standard and the errors Lin (1989), Feng et al. (2015), and Chabert et al. (2019), was used for the ranges in each pixel.

\section{Range 1}

(B)

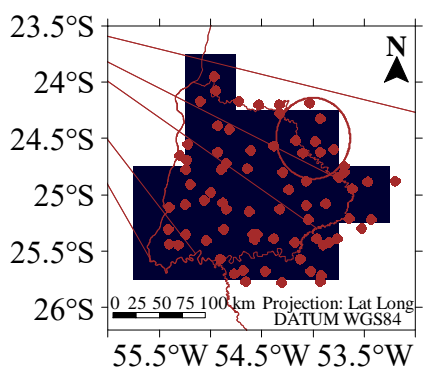

(C)

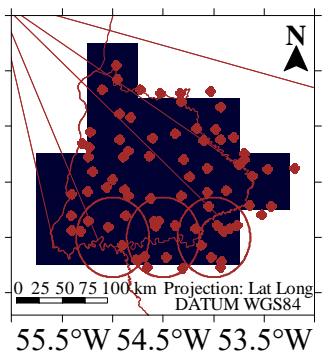

(D)

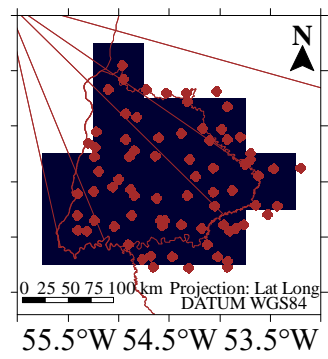

(E)

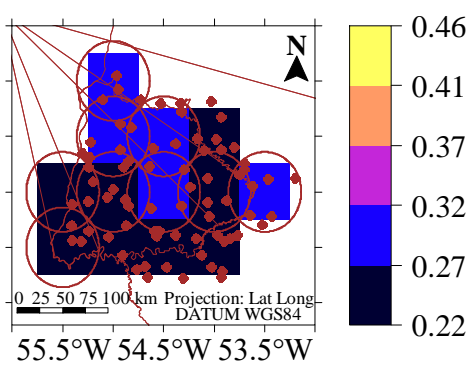

Range 2

(B)

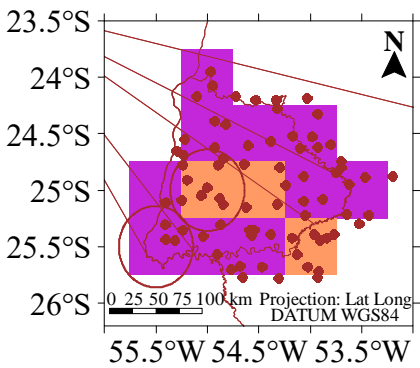

$55.5^{\circ} \mathrm{W} 54.5^{\circ} \mathrm{W} 53.5^{\circ} \mathrm{W}$
(C)

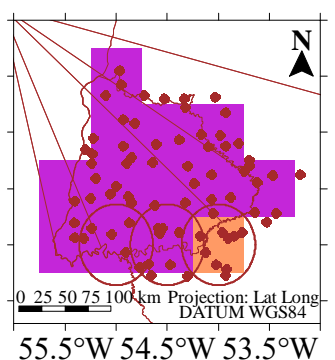

(D)

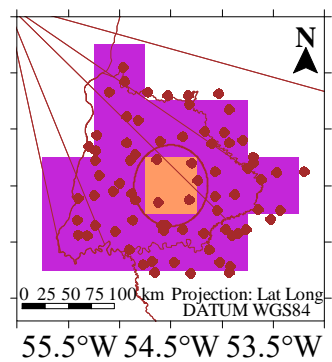

(E)

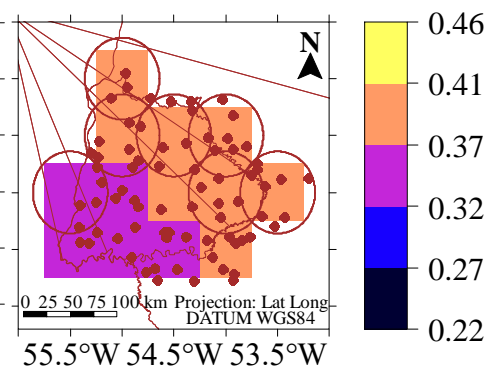

Range 3

(B)

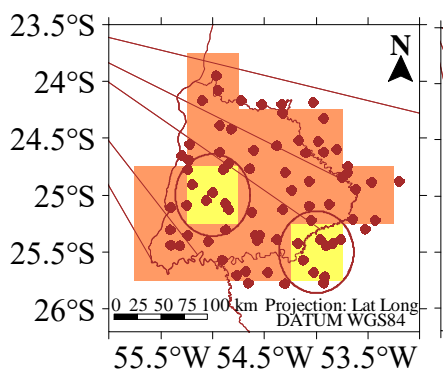

(C)

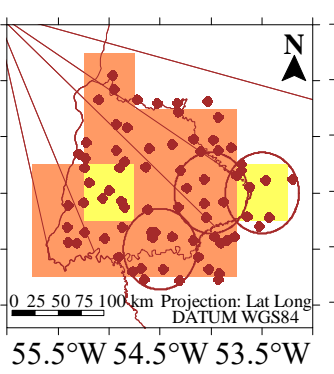

(D)

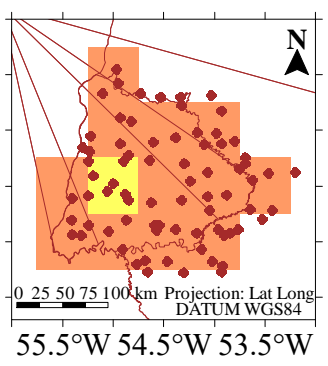

(E)

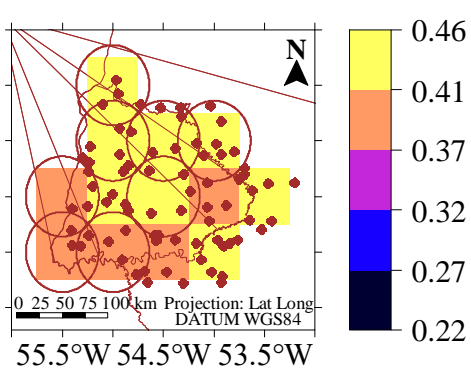




\section{Range 4}

(B)

(C)

(D)

(E)

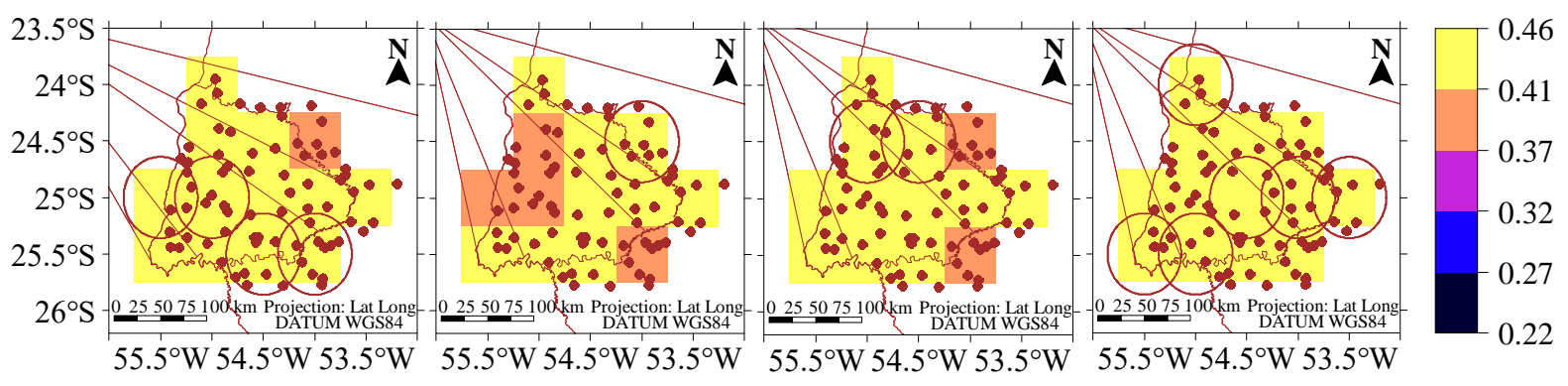

Figure 2. Concordances for the ranges 1-4 between gold standard (ANA) measures and the forecasts of the centers CMC (A), ECMWF (B), NCEP (C) and CPTEC (D) in each pixel of the West mesoregion of Paraná-Brazil. The circles indicate the centers with the highest agreement

The results presented in Figure 2 suggest that a calibration procedure must be applied before a precipitation forecast is used. According to Li et al. (2008), calibration procedures are required to remove bias and increase accuracy of spatial data. The selection of a forecast model should consider the highest value of concordance with gold standard (Harris et al., 2001; Barnhart et al., 2007).

The percentage of selected centers, which were indicated by circles in Figure 2, for each range were as follows: range 1: 7,7\% of CMC, $23,1 \%$ of ECMWF, and $69,2 \%$ of the CPTEC; range 2: $15,4 \%$ of CMC, $23,1 \%$ of ECMWF, 7,7\% of NCEP, and 53,8\% of the CPTEC; range 3: $15,4 \%$ of CMC, $23,1 \%$ of ECMWF, and $61,5 \%$ of the CPTEC; and in range $4,30,8 \%$ of CMC, $7,7 \%$ of ECMWF, $15,4 \%$ of NCEP, and $46,1 \%$ of the CPTEC.

For the concordances in each range, which were indicated by circles in Figure 2 95\% confidence limits for $\rho$ were estimated, using the bootstrapping pairs method according to Chernick and LaBudde (2011). The values of the 95\% lower confidence limits (LCL) and 95\% upper confidence limits (UCL) are presented in Table 3. Therefore, the selection of rainfall forecasts from the four CMC, ECMWF, NCEP, and CPTEC centers for use in yield estimation models should follow the Table 3 for crops such as soybean grown in the study period.

The qq-plots are presented in Figure 3 for the three-parameter gamma distribution, using the gold standard data grouped in ten-day periods and the corresponding $240 \mathrm{~h}$ range of the centers CMC, ECMWF, NCEP, and CPTEC. The three-parameter gamma distribution presented better data fit when compared to the normal distribution. 
Table 3. Estimated concordances with lower and upper 95\% confidence limits for the selected centers, which were indicated by circles in Figure 2, considering each range in the 13 pixels of the West mesoregion of Paraná-Brazil

\begin{tabular}{|c|c|c|c|c|c|c|c|c|c|}
\hline \multicolumn{10}{|c|}{ Range 1} \\
\hline \multirow{2}{*}{$\mathrm{P}$} & \multirow{2}{*}{ SEL } & \multirow{2}{*}{$\hat{\rho}$} & \multicolumn{2}{|c|}{$\mathrm{CL}$} & \multirow{2}{*}{$\mathrm{P}$} & \multirow{2}{*}{ SEL } & \multirow{2}{*}{$\hat{\rho}$} & \multicolumn{2}{|c|}{$\mathrm{CL}$} \\
\hline & & & LCL & UCL & & & & $\mathrm{LCL}$ & UCL \\
\hline 1 & CPTEC & 0.298 & 0.238 & 0.391 & 8 & СРТЕC & 0.270 & 0.219 & 0.361 \\
\hline 2 & CPTEC & 0.289 & 0.233 & 0.371 & 9 & СРТЕC & 0.293 & 0.235 & 0.388 \\
\hline 3 & CPTEC & 0.282 & 0.225 & 0.375 & 10 & CPTEC & 0.251 & 0.209 & 0.317 \\
\hline 4 & CMC & 0.259 & 0.212 & 0.336 & 11 & ECMWF & 0.255 & 0.202 & 0.336 \\
\hline 5 & CPTEC & 0.272 & 0.220 & 0.353 & 12 & ECMWF & 0.253 & 0.208 & 0.313 \\
\hline 6 & CPTEC & 0.267 & 0.221 & 0.332 & 13 & ECMWF & 0.252 & 0.202 & 0.315 \\
\hline 7 & CPTEC & 0.285 & 0.235 & 0.359 & & & & & \\
\hline \multicolumn{10}{|c|}{ Range 2} \\
\hline \multirow{2}{*}{$\mathrm{P}$} & \multirow{2}{*}{ SEL } & \multirow{2}{*}{$\hat{\rho}$} & \multicolumn{2}{|c|}{$\mathrm{CL}$} & \multirow{2}{*}{$\mathrm{P}$} & \multirow{2}{*}{ SEL } & \multirow{2}{*}{$\hat{\rho}$} & \multicolumn{2}{|c|}{$\mathrm{CL}$} \\
\hline & & & $\mathrm{LCL}$ & UCL & & & & LCL & UCL \\
\hline 1 & CPTEC & 0.385 & 0.382 & 0.471 & 8 & СРТЕC & 0.383 & 0.378 & 0.455 \\
\hline 2 & CPTEC & 0.387 & 0.381 & 0.444 & 9 & CPTEC & 0.385 & 0.365 & 0.448 \\
\hline 3 & CPTEC & 0.393 & 0.375 & 0.451 & 10 & CMC & 0.346 & 0.339 & 0.436 \\
\hline 4 & CPTEC & 0.398 & 0.377 & 0.459 & 11 & ECMWF & 0.358 & 0.341 & 0.440 \\
\hline 5 & CPTEC & 0.359 & 0.348 & 0.452 & 12 & ECMWF & 0.356 & 0.352 & 0.432 \\
\hline 6 & CMC & 0.372 & 0.359 & 0.452 & 13 & ECMWF & 0.382 & 0.374 & 0.408 \\
\hline 7 & NCEP & 0.384 & 0.379 & 0.440 & & & & & \\
\hline \multicolumn{10}{|c|}{ Range 3} \\
\hline \multirow{2}{*}{$\mathrm{P}$} & \multirow{2}{*}{ SEL } & \multirow{2}{*}{$\hat{\rho}$} & \multicolumn{2}{|c|}{$\mathrm{CL}$} & \multirow{2}{*}{$\mathrm{P}$} & SEL & $\hat{A}$ & & \\
\hline & & & LCL & UCL & & & $\rho$ & LCL & UCL \\
\hline 1 & CPTEC & 0.424 & 0.365 & 0.451 & 8 & ECMWF & 0.413 & 0.409 & 0.417 \\
\hline 2 & CPTEC & 0.432 & 0.399 & 0.410 & 9 & ECMWF & 0.430 & 0.350 & 0.464 \\
\hline 3 & CPTEC & 0.428 & 0.385 & 0.450 & 10 & CPTEC & 0.392 & 0.387 & 0.392 \\
\hline 4 & CPTEC & 0.426 & 0.368 & 0.454 & 11 & CPTEC & 0.400 & 0.391 & 0.400 \\
\hline 5 & CPTEC & 0.407 & 0.373 & 0.428 & 12 & ECMWF & 0.403 & 0.390 & 0.404 \\
\hline 6 & $\mathrm{CMC}$ & 0.426 & 0.415 & 0.430 & 13 & $\mathrm{CMC}$ & 0.416 & 0.379 & 0.435 \\
\hline 7 & CPTEC & 0.423 & 0.378 & 0.444 & & & & & \\
\hline & & & & & & & & & \\
\hline$P$ & SEL & ล & & & $\mathrm{P}$ & SEL & $\widehat{a}$ & & \\
\hline & & $\rho$ & $\mathrm{LCL}$ & $\mathrm{UCL}$ & & & $\rho$ & LCL & UCL \\
\hline 1 & CPTEC & 0.463 & 0.405 & 0.491 & 8 & СРТЕC & 0.448 & 0.390 & 0.471 \\
\hline 2 & NCEP & 0.445 & 0.371 & 0.446 & 9 & CPTEC & 0.444 & 0.399 & 0.464 \\
\hline 3 & NCEP & 0.445 & 0.357 & 0.460 & 10 & СРТЕC & 0.437 & 0.400 & 0.458 \\
\hline 4 & ECMWF & 0.420 & 0.381 & 0.468 & 11 & CPTEC & 0.437 & 0.405 & 0.451 \\
\hline 5 & $\mathrm{CMC}$ & 0.455 & 0.445 & 0.466 & 12 & $\mathrm{CMC}$ & 0.430 & 0.399 & 0.443 \\
\hline 6 & CMC & 0.443 & 0.415 & 0.454 & 13 & CMC & 0.418 & 0.404 & 0.428 \\
\hline 7 & CPTEC & 0.448 & 0.393 & 0.465 & & & & & \\
\hline
\end{tabular}

Note: P: Pixel number, SEL: Selected center, ${ }^{\hat{\rho}}$ : Estimated concordance index, CL: $95 \%$ confidence limits for populational ${ }^{P}$, LCL: $95 \%$ lower confidence limit, UCL: $95 \%$ upper confidence limit. 


\section{Range 1}
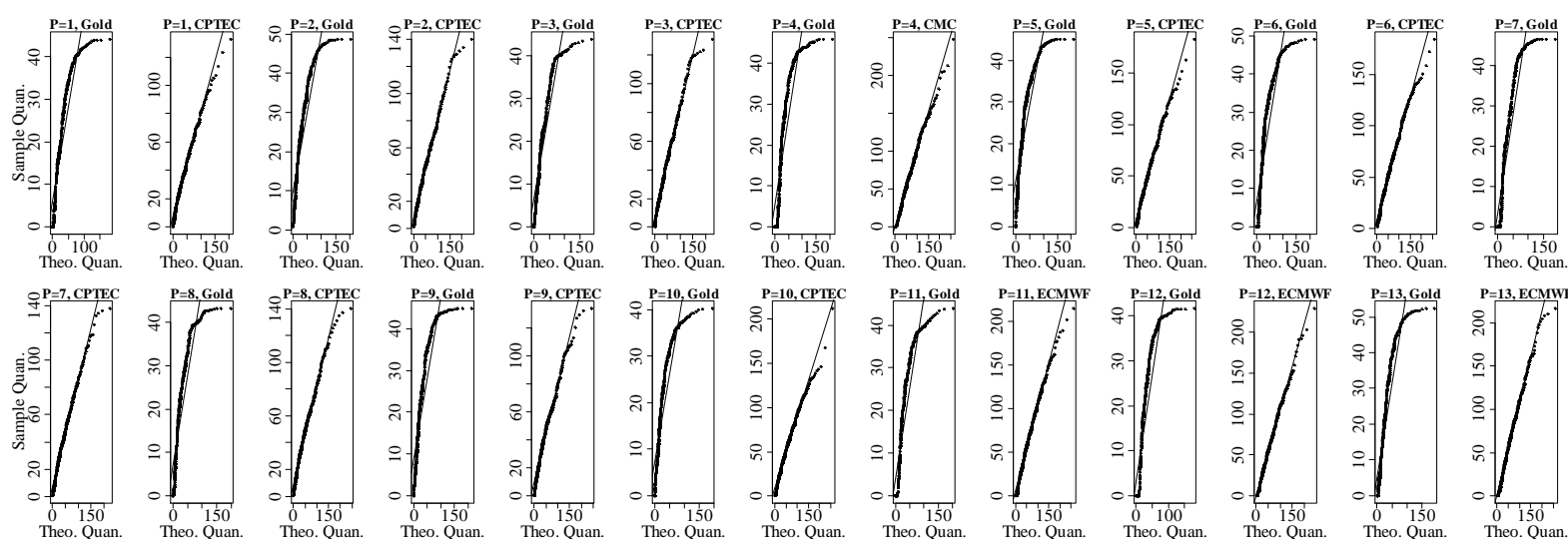

\section{Range 2}
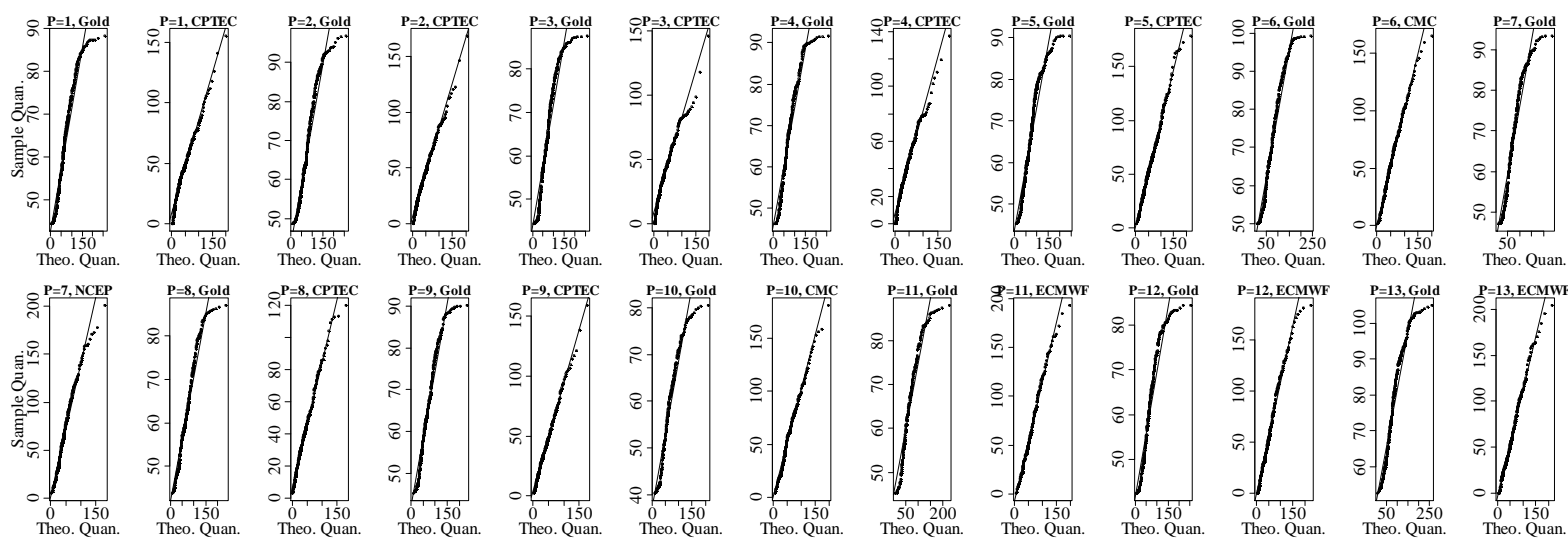

Range 3
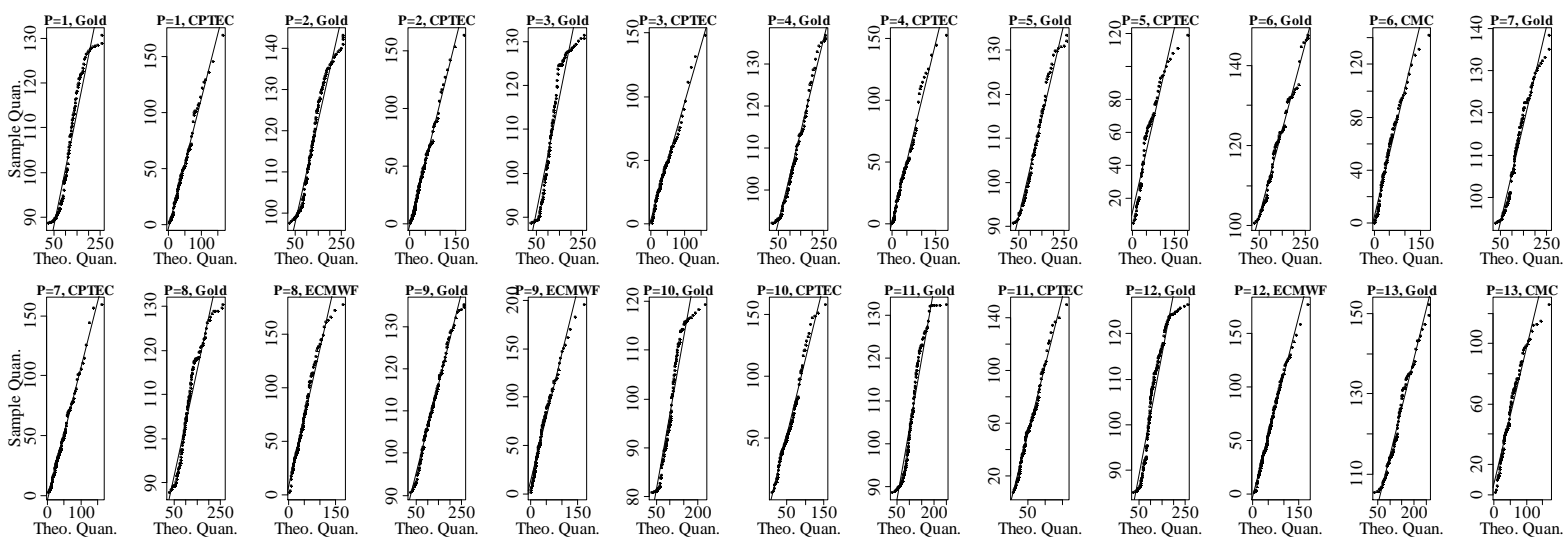

Range 4 

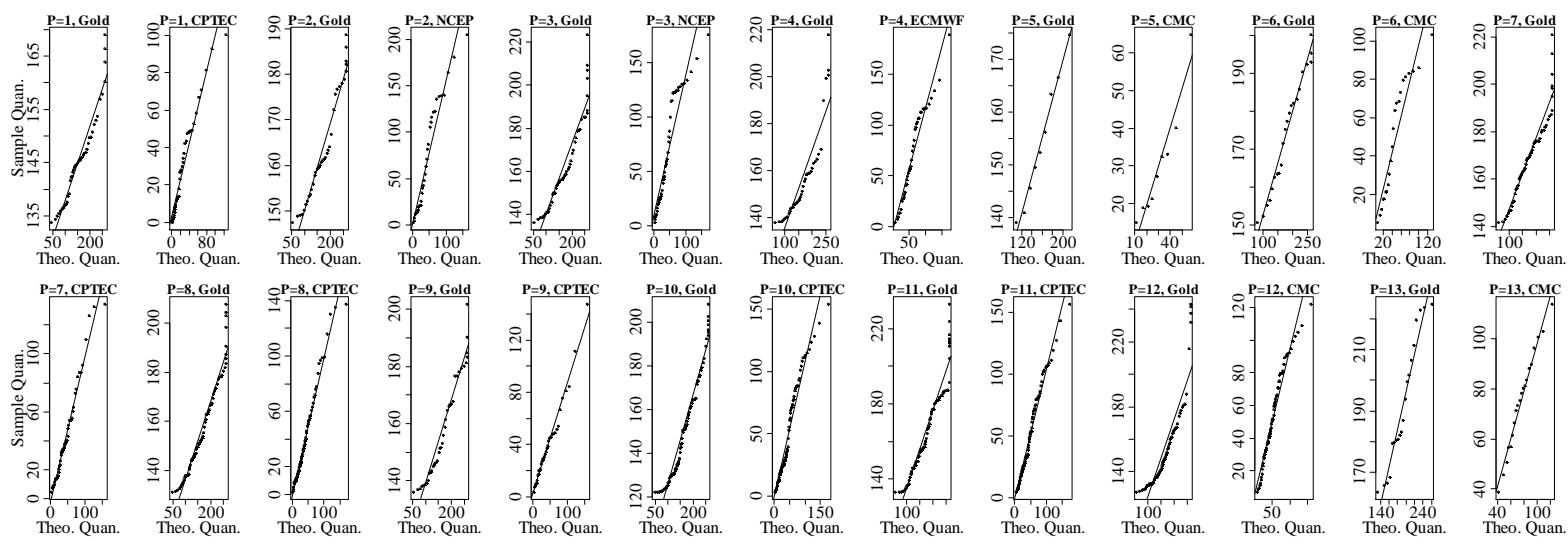

Figure 3. QQ-plots for the three-parameter gamma distribution, considering the gold standard and the selected centers for each range in the 13 pixels of the West mesoregion of Paraná.

\section{Conclusions}

The estimated population variances for the gold standard measures and the errors of measurements, which were obtained with their respective distribution, allowed detecting spatial variability of the concordances in the study area. The detected variability was independent of forecast centers CMC, ECMWF, NCEP, and CPTEC. The geographical location and the range of precipitation should be considered when choosing a forecast center.

The estimated concordances using multivariate gamma distribution suggest that a calibration procedure, which aims to increase accuracy of spatial data, must be applied to the forecast data, before a precipitation forecast is used in a crop yield estimated model.

The crop yield estimates for soybean should use predictions from selected centers at locations within that pixel. For rainfall forecasts to be used in a yield estimation model of other crop cultures, a concordance analysis is required and should be applied according to crop development cycle to select the center.

The correspondence between the reference measurements, which are obtained from meteorological stations, and the climate model data from centers CMC, ECMWF, NCEP, and CPTEC requires that the geographical location and the precipitation range are respectively matched. A spatial correspondence of reference measures with climate model data can be obtained using the precipitation average value of the meteorological stations with distance from the centroid of pixel and which covers the pixel area. For the correspondence of precipitation range, the ten-day grouped period can be applied.

The confidence intervals for the concordances of selected centers CMC, ECMWF, NCEP or CPTEC indicated small variability for each precipitation range. The ranges 3 and 4 of precipitation with values between 122.18 and $244.36 \mathrm{~mm}$, in general, presented the highest agreements with gold standard measures. The highest concordances in ranges 3 and 4 suggest that the forecast models used by centers CMC, ECMWF, NCEP, and CPTEC are more suitable for detection of extreme precipitation events, above $100 \mathrm{~mm}$.

The multivariate gamma and the gamma difference distributions were used as an alternative to the normal distribution. The fitted gamma distribution for precipitation data from gold 
standard and centers of forecast, and the fitted gamma difference distribution for the errors were more suitable as compared to normal distribution.

\section{Acknowledgements}

The authors are grateful for the partial financial support from UTFPR, UNIOESTE / PGEAGRI, Coordination for the Improvement of Higher Level Personnel - Brazil (CAPES) - Finance Code 001, National Technological and Scientific Development (CNPq), and FONDECYT Chile (Project No. 1150325).

\section{References}

ADAPAR. Agência de Defesa Agropecuária do Paraná. (2018). Estabelece o período do vazio sanitário, as datas limites para semeadura e colheita da soja, e outras medidas para o controle da ferrugem asiática (Phakopsora pachyrhizi) no Estado do Paraná. Portaria n. 264 de 17 de setembro de 2018. Curitiba, Paraná: Paraná.

Aminyavari, S., Saghafian, B., \& Delavar, M. (2018). Evaluation of TIGGE Ensemble Forecasts of Precipitation in Distinct Climate Regions in Iran. Advances in Atmospheric Sciences, 35(4), 457-468. https://doi.org/10.1007/s00376-017-7082-6

Barnhart, H. X., Haber, M. J., \& Lin, L. I. (2007). An Overview on Assessing Agreement with Continuous Measurements. Journal of Biopharmaceutical Statistics, 17(4), 529-569. https://doi.org/10.1080/10543400701376480

Battisti, R., Sentelhas, P. C., \& Boote, K. J. (2018). Sensitivity and requirement of improvements of four soybean crop simulation models for climate change studies in Southern Brazil. International Journal of Biometeorology, 62(5), 823-832. https://doi.org/10.1007/s00484-017-1483-1

Bezabih, M., \& Di Falco, S. (2012). Rainfall variability and food crop portfolio choice: evidence from Ethiopia. Food Security, 4(4), 557-567. https://doi.org/10.1007/s12571-012-0219-7

Bornhofen, E., Benin, G., Galvan, D., \& Flores, M. F. (2015). Épocas de semeadura e desempenho qualitativo de sementes de soja. Pesquisa Agropecuária Tropical, 45, 46-55. https://doi.org/10.1590/1983-40632015v4529143

Broyden, C. G. (1970). The Convergence of a Class of Double-Rank Minimization Algorithms 1. General Considerations. IMA Journal of Applied Mathematics, 6(1), 76-90. https://doi.org/10.1093/imamat/6.1.76

Cera, J. C., Streck, N. A., Fensterseifer, C. A. J., Ferraz, S. E. T., Bexaira, K. P., Silveira, W. B., $\&$ Cardoso, Â. P. (2017). Soybean yield in future climate scenarios for the state of Rio Grande do Sul, Brazil. Pesquisa Agropecuária Brasileira, 52, 380-392. https://doi.org/10.1590/s0100-204x2017000600002 
Chabert, A., Amossé, A., \& Sarthou, J. P. (2019). Assessing landscape composition using visual assessment: accuracy of rapid description compared to digital mapping. Landscape Research, 44(1), 6-18. https://doi.org/10.1080/01426397.2017.1392493

Cheng, R. C. H., \& Amin, N. A. K. (1983). Estimating Parameters in Continuous Univariate Distributions with a Shifted Origin. Journal of the Royal Statistical Society. Series B (Methodological), 45(3), 394-403. https://doi.org/10.1111/j.2517-6161.1983.tb01268.x

Cherian, K. C. (1941). A Bi-Variate Correlated Gamma-Type Distribution Function. Journal of the Indian Mathematical Society, 5, 133-144.

Chernick, M. R., \& LaBudde, R. A. (2011). An Introduction to Bootstrap Methods with Applications to R. New Jersey: John Wiley \& Sons, Inc.

Confalone, A. E., Bernardes, M. S., Costa, L. C., Righi, C. A., Dourado Neto, D., Martin, T. N., $\&$ Pereira, C. R. (2010). Expolinear model on soybean growth in Argentina and Brazil. Ciência Rural, 40, 1009-1016. https://doi.org/10.1590/S0103-84782010000500002

Cristaldo, M. F., Souza, C. C. de, Jesus, L. de, Padovani, C. R., Oliveira, P. T. S. de, \& Viganó, H. H. da G. (2017). Analysis and Distribution of the Rainfall Monitoring Network in a Brazilian Pantanal Region. Revista Brasileira de Meteorologia, 32, 199-205. https://doi.org/10.1590/0102-77863220007

Donner, A. (1986). A Review of Inference Procedures for the Intraclass Correlation Coefficient in the One-Way Random Effects Model. International Statistical Review / Revue Internationale de Statistique, 54(1), 67-82. https://doi.org/10.2307/1403259

Feng, D., Baumgartner, R., \& Svetnik, V. (2015). A Robust Bayesian Estimate of the Concordance Correlation Coefficient. Journal of Biopharmaceutical Statistics, 25(3), 490-507. https://doi.org/10.1080/10543406.2014.920342

Fleiss, J. L. (1999). The Design and Analysis of Clinical Experiments. New York: Wiley. https://doi.org/10.1002/9781118032923

Fletcher, R. (1970). A new approach to variable metric algorithms. The Computer Journal, 13(3), 317-322. https://doi.org/10.1093/comjnl/13.3.317

Galea, M. (2013). Comparación de métodos de medición en presencia de un gold standar. Estadística, 65(185), 1-17.

Goldfarb, D. (1970). A Family of Variable-Metric Methods Derived by Variational Means. Mathematics of Computation, 24(109), 23-26. https://doi.org/10.2307/2004873

Harris, I. R., Burch, B. D., \& Laurent, R. T. St. (2001). A blended estimator for a measure of agreement with a gold standard. Journal of Agricultural, Biological, and Environmental Statistics, 6(3), 326. https://doi.org/10.1198/108571101317096541

Hasan, M. M., Croke, F. B., \& Karim, F. (2019). Spatial and Seasonal Variations and Inter-Relationship in Fitted Model Parameters for Rainfall Totals across Australia at Various Timescales. Climate, 7(1). https://doi.org/10.3390/cli7010004 
Iglesias, A., Quiroga, S., Moneo, M., \& Garrote, L. (2012). From climate change impacts to the development of adaptation strategies: Challenges for agriculture in Europe. Climatic Change, 112(1), 143-168. https://doi.org/10.1007/s10584-011-0344-x

Jajoria, D. K., Sharma, S. K., Narolia, G. P., \& Dotaniya, M. L. (2015). Rainfall Variability: A Tool for Crop Planning of Udaipur Region of India. National Academy Science Letters, 38(2), 95-98. https://doi.org/10.1007/s40009-014-0305-9

Jensen, D. R. (1970). The Joint Distribution of Quadratic Forms and Related Distributions. Australian Journal of Statistics, 12(1), 13-22.

https://doi.org/10.1111/j.1467-842X.1970.tb00108.x

Jha, S. K., Shrestha, D. L., Stadnyk, T. A., \& Coulibaly, P. (2018). Evaluation of ensemble precipitation forecasts generated through post-processing in a Canadian catchment. Hydrol. Earth Syst. Sci., 22(3), 1957-1969. https://doi.org/10.5194/hess-22-1957-2018

Johnson, N. L., Kotz, S., \& Balakrishnan, N. (1994). Continuous Univariate Distributions. New York: Wiley.

Laurent, R. T. St. (1998). Evaluating Agreement with a Gold Standard in Method Comparison Studies. Biometrics, 54(2), 537-545. https://doi.org/10.2307/3109761

Li, B., Eriksson, M., Srinivasan, R., \& Sherman, M. (2008). A geostatistical method for Texas NexRad data calibration. Environmetrics, 19(1), 1-19. https://doi.org/10.1002/env.848

Lin, L. I. K. (1989). A Concordance Correlation Coefficient to Evaluate Reproducibility. Biometrics, 45(1), 255-268. https://doi.org/10.2307/2532051

Lord, F. M., \& Novick, M. R. (1968). Statistical Theories of Mental Test Scores. Massachusetts: Addison-Wesley.

Mathal, A. M. (1993). On Noncentral Generalized Laplacianness of Quadratic Forms in Normal Variables. Journal of Multivariate Analysis, 45(2), 239-246.

https://doi.org/10.1006/jmva.1993.1036

Mathal, A. M., \& Moschopoulos, P. G. (1992). A form of multivariate gamma distribution. Annals of the Institute of Statistical Mathematics, 44(1), 97-106.

https://doi.org/10.1007/BF00048672

McKay, A. T. (1934). Sampling from Batches. Supplement to the Journal of the Royal Statistical Society, 1(2), 207-216. https://doi.org/10.2307/2983603

Meotti, G. V., Benin, G., Silva, R. R., Beche, E., \& Munaro, L. B. (2012). Épocas de semeadura e desempenho agronômico de cultivares de soja. Pesquisa Agropecuária Brasileira, 47, 14-21. https://doi.org/10.1590/S0100-204X2012000100003

Moraes, R. A., Rocha, J. V., \& Lamparelli, R. A. C. (2014). Determination of total accumulated rainfall, global radiation, evapotranspiration and degree-days originated from the ECMWF model to sugar cane crop. Engenharia Agrícola, 34, 322-331.

https://doi.org/10.1590/S0100-69162014000200013 
Nunes, M. S., Robaina, A. D., Peiter, M. X., Braga, F. de V. A., Pereira, T. dos S., \& Buske, T. C. (2016). Resposta da produção de soja à variabilidade espacial sob pivô central. Brazilian Journal of Irrigation and Drainage, 19-27. https://doi.org/10.15809/irriga.2016v1n1p19-27

Pugh, S., Heaton, M. J., Svedin, J., \& Hansen, N. (2019). Spatiotemporal Lagged Models for Variable Rate Irrigation in Agriculture. Journal of Agricultural, Biological and Environmental Statistics, 1-17. https://doi.org/10.1007/s13253-019-00365-3

R Core Team. (2019). R: A Language and Environment for Statistical Computing. $R$ Foundation for Statistical Computing, Vienna, Austria. Retrieved from

https://www.r-project.org/

Rodrigues, T. R., Casaroli, D., Evangelista, A. W. P., \& Alves Júnior, J. (2017). Water availability to soybean crop as a function of the least limiting water range and evapotranspiration. Pesquisa Agropecuária Tropical, 47, 161-167.

https://doi.org/10.1590/1983-40632016v4743746

Royen, T. (1991). Expansions for the multivariate chi-square distribution. Journal of Multivariate Analysis, 38(2), 213-232. https://doi.org/10.1016/0047-259X(91)90041-Y

Sadiq, N. (2014). Stochastic Modelling of the Daily Rainfall Frequency and Amount. Arabian Journal for Science and Engineering, 39(7), 5691-5702.

https://doi.org/10.1007/s13369-014-1132-5

Shanno, D. (1970). Conditioning of Quasi-Newton Methods for Function Minimization. Mathematics of Computation, 24(111), 647-656. https://doi.org/10.2307/2004840

Souza, P. J. de O. P., Ortega-Farias, S., Rocha, E. J. P. da, Sousa, A. M. L. de, \& Souza, E. B. de. (2016). Consumo hídrico da soja no nordeste paraense. Brazilian Journal of Irrigation and Drainage, $x x$, 218-231. https://doi.org/10.15809/irriga.2016v1n01p218-231

Vivan, G. A., Peiter, M. X., Robaina, A. D., Barboza, F. da S., \& Buske, T. (2013). Rendimento relativo da cultura da soja em função da lâmina de irrigação. Brazilian Journal of Irrigation and Drainage, 18(2), 282-292. https://doi.org/10.15809/irriga.2013v18n2p282

Zandonadi, L., Acquaotta, F., Fratianni, S., \& Zavattini, J. A. (2016). Changes in precipitation extremes in Brazil (Paraná River Basin). Theoretical and Applied Climatology, 123(3), 741-756. https://doi.org/10.1007/s00704-015-1391-4

Zanon, A. J., Streck, N. A., \& Grassini, P. (2016). Climate and Management Factors Influence Soybean Yield Potential in a Subtropical Environment. Agronomy Journal, 108, 1447-1454. https://doi.org/10.2134/agronj2015.0535

\section{Copyright Disclaimer}

Copyright for this article is retained by the author(s), with first publication rights granted to the journal.

This is an open-access article distributed under the terms and conditions of the Creative Commons Attribution license (http://creativecommons.org/licenses/by/4.0/). 